\title{
DIMENSIONAL VERIFICATION AND QUALITY CONTROL OF IMPLANTS PRODUCED BY ADDITIVE MANUFACTURING
}

\author{
DOI: 10.12776/QIP.V19I1.393
}

\author{
TEODOR TÓTH, RADOVAN HUDÁK, JOZEF ŽIVČÁK
}

Received 02 September 2014, Revised 01 December 2014, Accepted 06 May 2015

\begin{abstract}
Purpose: Development of computer technology and alternative manufacturing methods in form of additive manufacturing leads to the manufacture of products with complex shapes. In the field of medicine they include, inter alia, custommade implants manufactured for a particular patient, such as cranial implants, maxillofacial implants, etc. With regard to the fact that such implants are inserted into a patient's body, it is necessary to perform the verification, including the shape and dimensional verification. The article deals with the application of the industrial computer tomography within the process of inspection and verification of selected custom-made implant types.
\end{abstract}

Methodology/Approach: The Department of Biomedical Engineering and Measurement performs the verification of medicinal products manufactured by the additive manufacturing technologies from the Ti-6Al-4V (Grade 5) titanium alloy, using the coordinate measuring machine Carl Zeiss Contura G2 and the industrial computed tomography machine Carl Zeiss Metrotom 1500. These equipment fulfil the requirements for the identification and evaluation of dimensions of both, the external and the internal structures.

Findings: The article presents the possibilities of the computed tomography utilisation in the inspection of individual implant manufacture using the additive manufacturing technologies. The results indicate that with the adjustment of appropriate input parameters (alignment), this technology is appropriate for the analysis of shape deviations, when compared with the CAD model.

Research Limitation/implication: With the increasing distance of measured object from X-ray source, the machine's resolution function decreases. Decreasing of resolution has a minor impact on the measured dimensions 
(relatively high tolerances), but has a significant impact on the evaluation of porosity and inclusions.

Originality/Value of paper: Currently, the verification of a manufactured implant can be carried out using 3D scanners and the industrial computed tomography. The use of 3D scanners is appropriate for the shape inspection, for example the shape of an implant's outer surface. The computed tomography is the only method for evaluation of shape deviations, defectoscopy and dimensional analysis in one measurement.

Keywords: individual implants; measurement; additive manufacturing; actualnominal comparison; defectoscopy

\section{INTRODUCTION}

Product quality is one of the factors that best present a particular manufacturer; hence the product quality control in all manufacture stages belongs to the most important processes.

Measuring devices used in the quality control process serve two fundamental purposes in the manufacture process. The first one is the manufacture implementation process, in which the primary function of measuring devices is the inspection of outputs in order to adjust and set the manufacture process. The second process is the inspection of products from the already implemented manufacture, in which products are inspected for meeting the requirements specified for example by the respective drawing documentation, with the concurrent inspection whether the manufacture process is maintained within the required limits.

Unlike implants manufactured with the additive manufacturing, CNC-type equipment, casting or injection might possess, in addition to dimensional deviations, also faults of internal structures. Inspection of these faults is significantly more demanding than inspection of dimensions. It is caused by a smaller number of procedures and technologies capable of identifying internal defects of materials. The most frequently used procedure is the inspection of a V-cut from the required area of the selected sample. The main disadvantages include the destruction of even a "good" product and the limitation to one or several precisely determined cuts through the inspected sample. We are currently witnessing a remarkable development of equipment using the concept of medical tomography, adjusted and applied to industrial conditions. These tomography equipment are suitable for metrological purposes, facilitating the inspection of not only external product dimensions but also the product volume. The equipment enable identification of internal defects in form of air bubbles or foreign materials. If the porosity of implant exceeded the limit, the patient health is at risk. 
For implants verification we use the coordinate measuring machine Carl Zeiss Contura G2 and the industrial computed tomography machine Carl Zeiss Metrotom 1500. These equipment fulfil the requirements for the identification and evaluation of dimensions of both, the external and the internal structures. The Contura G2 equipment with a rotary measuring head RDS/VAST XXT facilitates the measurement of products with the dimensions of $700 \times 1000 \times 600 \mathrm{~mm}$ with the maximum permissible error $\mathrm{MPEE}=(1.8+\mathrm{L} / 300) \mu \mathrm{m}$, where $\mathrm{L}$ is a measured length expressed in mm (pursuant to the STN EN ISO 10360-1 standard, section 9.2). The industrial computed tomography machine Metrotom 1500 with the power of $225 \mathrm{kV} / 225 \mathrm{~W}$ and the detector with the resolution of $1024 \times 1024$ pixels enriches the possibilities of the dimension measuring with the measurement of internal product dimensions, evaluation of product shape deviations, and defectoscopy. The equipment facilitates scanning of objects with the maximum diameter of $\Phi 300 \mathrm{~mm}$ and the height of $300 \mathrm{~mm}$ with the maximum permissible error $\mathrm{MPEE}=(9+\mathrm{L} / 50) \mu \mathrm{m}$.

The article presents the possibilities of the computed tomography utilisation in the inspection of individual implant manufacture using the additive manufacturing technologies. The results indicate that with the adjustment of appropriate input parameters (alignment), this technology is appropriate for the analysis of shape deviations, when compared with the CAD model. Subsequently, the tools facilitate identification of deviations at any implant location, and after the assessment requirements (tolerances) are determined, the conclusion can be made regarding the outcome's compliance with the requirements. The computed tomography is also a tool facilitating the detection of potential pores and inclusions inside an implant.

\section{COMPUTED TOMOGRAPHY AND ADDITIVE MANUFACTURING}

Computed tomography belongs to the radiodiagnostic methods and uses the X-radiation for the penetration. The Department of Biomedical Engineering and Measurement possesses the Metrotom 1500 tomography machine manufactured by the Carl Zeiss company with a $1 \mathrm{M}$ pixel detector. After an examined object is inserted inside, it is necessary to select the scanning parameters (output, scanning distance, etc.) and the number of projections to be obtained per one rotation of the scanned object. Obtained projections are processed into a point cloud (points in the scanned volume defined by the coordinates and the colour which represents the density in a particular location). Subsequent processing is then performed by the user who can assess the obtained scan on the basis of surface determination (reconstruction of the digitalised object surface). Figure 1 represents the computed tomography principle scheme and the subsequent image processing. 


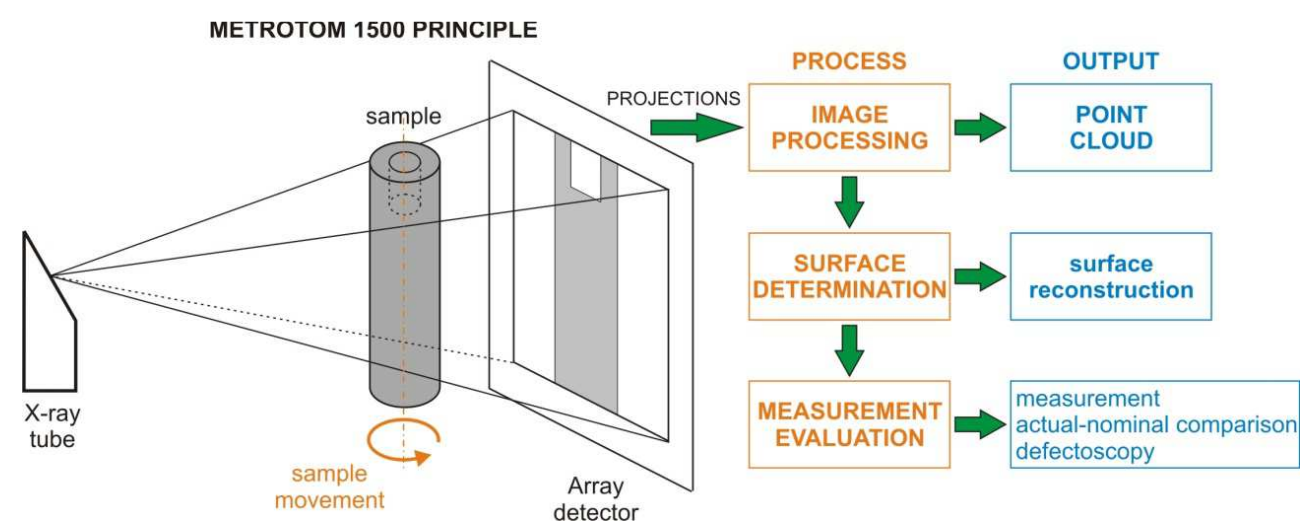

Figure 1 - Metrotom 1500 Principle

Additive manufacturing, unlike conventional manufacturing technologies, such as the $\mathrm{CNC}$ where an object is manufactured by removing the material, applies the principle of sequential addition of the material. The object is manufactured layer by layer, as the blade applies a layer of powder on the base, subsequently the laser sinters the powder at required locations, the base lowers one layer and the subsequent powder layer is deposited (Figure 2). This process is repeated until the entire object is manufactured. The manufacture is followed by the postprocessing in form of annealing and surface finishing (Brown et al., 2014, Živčák et al., 2013).

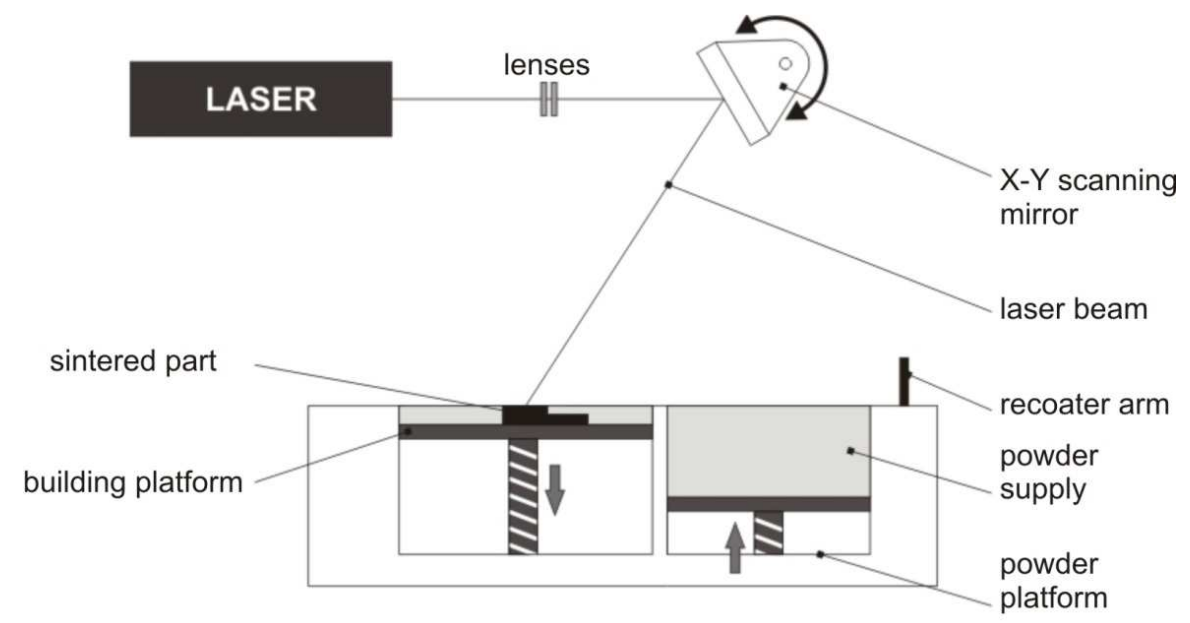

Figure 2 - DMLS Technology Principle

\section{UTILISATION OF THE COMPUTED TOMOGRAPHY IN THE CUSTOM-MADE IMPLANT MANUFACTURE USING THE AM}

Unlike conventional engineering applications where majority of objects or their parts can be described using elementary 2D and 3D elements (plane, circle, 
roller, ...), individual implants are mostly formed of curves. Therefore, the preparation of any drawings as well as the verification of the manufactured implant by conventional measuring technologies (CMM, conventional gauges, ...) is difficult to perform. Currently, the verification of a manufactured implant can be carried out using 3D scanners and the industrial computed tomography. The use of 3D scanners is appropriate for the shape inspection, for example the shape of an implant's outer surface. In case of the comprehensive inspection of the entire implant, it is appropriate to use the computed tomography that provides the data regarding the surface, as well as the content, and is less time-consuming.

Computed tomography can be used in the three following areas:

- shape deviations inspection,

- defectoscopy,

- dimensional analysis.

Some authors use computed tomography for evaluation of porosity in a laser sintered artefacts or implants.

Léonard, et al. (2012) in study "Assessment by X-ray CT of the effects of geometry and build direction on defects in titanium ALM parts" demonstrated that X-ray computed tomography is a powerful tool for fully characterizing, in $3 \mathrm{D}$, the typical defects seen in titanium ALM components. Not only the whole specimen can be examined, but the exact size, shape, maximum dimension and location of the pores can be obtained whilst it is impossible from 2D metallographic sections.

Slotwinski and Garboczi (2013) in "Porosity of Additive Manufacturing Parts for Process Monitoring" describe the usage of ultrasonic porosity sensor for $0.2 \%$ change in porosity for $\mathrm{CoCr}$ alloy and compare it with CT.

Girardin, et al. (2011) in "Characterization of Porosity in a Laser Sintered MMCp Using X-Ray Synchrotron Phase Contrast Microtomography" use for characterization of porosity in a laser sintered metal matrix composite X-ray synchrotron.

For shape validation only the authors use various devices like coordinate measuring machines and 3D scanners. The CMM machines measure only in few defined points and we don't obtain the whole geometry of measured object. With 3D scanners we obtain the whole surface geometry but with worst accuracy. The accuracy of scanners is given in tenths of a millimetre and the accuracy of CT is in microns.

For deviation analysis Drstvensek, et al. (2008) in "Applications of Rapid Prototyping in Cranio-Maxilofacial Surgery Procedures" use for craniomaxilofacial implat shape validation the GOM ATOS II optical scanner. 
Salmi (2013) use in "Medical applications of additive manufacturing in surgery and dental care" Carl Zeiss C700 coordinate measuring machine for validation of plastic 3D model and the occlusal splints are verify by 3D scanners.

Podshivalov, et al. (2013) in "Design, Analysis and Additive Manufacturing of Porous Structures for Biocompatible Micro-Scale Scaffolds" use micro CT for verification of micro-scale bone scaffold printed by additive manufacturing.

Bauza, et al. (2014) in "Study of accuracy of parts produced using additive manufacturing" use tomograph Zeiss Metrotom 1500 and coordinate measuring machine Zeiss Contura G2 for verification of two artefacts built from stainless steel on an EOS M270 machine.

Matilainen (2012) in his work "Benchmarking of laser additive manufacturing process - bachelor thesis" describes the specimens created for verification of different additive manufacturing processes. For verification of LAM machine he design own artefact from EOS PH1 material (stainless steel) and provide dimensional verification of artefact.

\subsection{Shape deviation inspection}

As it is often difficult to assess particular dimensions of custom-made implants, an alternative method used is the comparison of the manufactured implant and the CAD model. Unlike particular values obtained by measurements, the outcome of such comparison is the map of deviations documenting the differences between the manufactured implant and the model. The advantage is the provision of the spatial distribution of deviations, not only the data representing the selected locations. The comparison of the scanned component and the CAD model requires their alignment. They are most frequently aligned applying the "Best Fit" method which uses the least squares principle, i.e. the deviations between the scan and the model are mathematically segmented. This method is not appropriate in cases when the obtained scan and the 3D model significantly differ at some locations, as the calculation might, in an effort to minimise the deviations, shift the alignment and thus the result must not necessarily correspond to the reality. Figure 3 represents the comparison of two identical objects applying the "Best Fit" method. 3D imaging displays only halves of the objects for the visualisation purposes. In this case, the shape deviation is zero. 


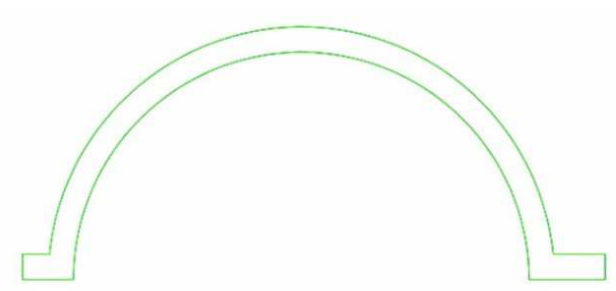

SECTION

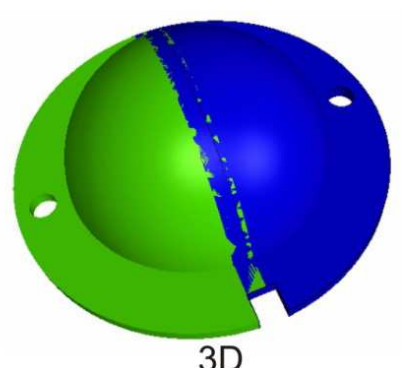

$3 \mathrm{D}$

Figure 3 - Comparison of Identical Objects

In case of significantly different objects (Figure 4), applying the "Best-Fit" method, their mutual shift (left) is clearly visible, as a result of the height change compensation. Consequently, this method is not suitable for the analysis. Figure 4 , the right part, represents a visible red band on the lower circular section, signalling the shift of the objects.

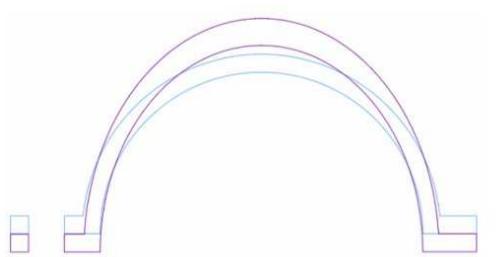

SECTION

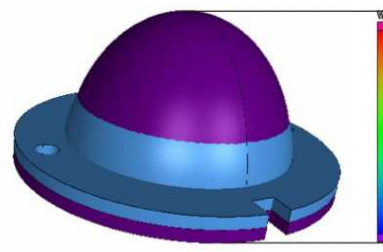

3D

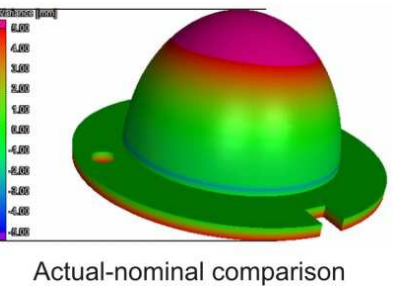

Actual-nominal comparison

Figure 4 -"Best-fit" Comparison

Figure 5 represents the comparison based on the "Face-Fit" principle, when individual objects are aligned according to the selected references. In this case, it was the alignment to the bottom plane and the groove. Figure 5, the left part, represents the cross-section of the overlapping objects; the central part shows the overlap in 3D; and the right part shows the comparison of the scanned object and the 3D model, whereas the green areas fall within the tolerances, red areas are marginal, and purple areas are beyond the tolerance.

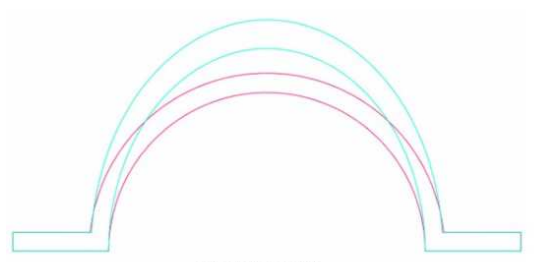

SECTION

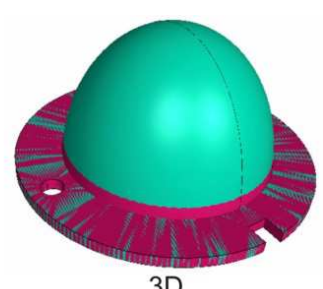

$3 \mathrm{D}$

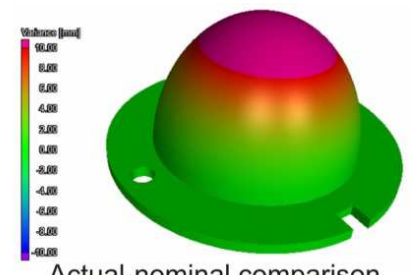

Actual-nominal comparison

Figure 5 - "Face-fit" Comparison

Figure 6, the left part, represents the obtained scan of the cranial implant and the right part shows the comparison with the CAD model. More significant 
deviations are visible in the scanning non-homogeneity areas. Locations intended for the implant attachment to the skull are within the tolerances.
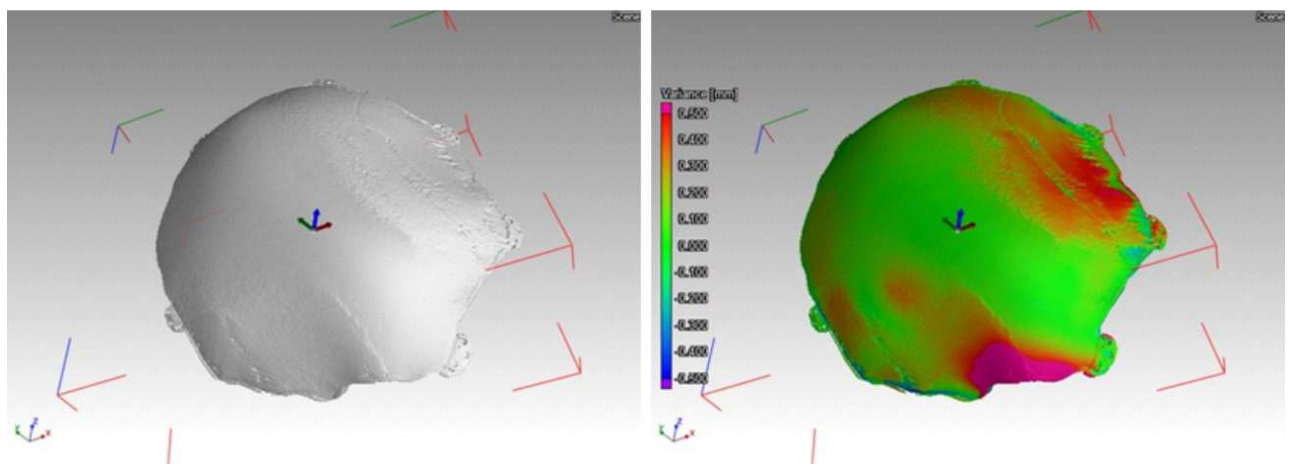

Figure 6-Cranial Implant - scan (left), comparison (right)

Figure 7, the left part, represents the comparison of the hip socket prosthesis and the CAD model. Significant deviations are caused by the noise resulting from the change of the implant cumulative thickness. Subsequently, the implant was locally treated.

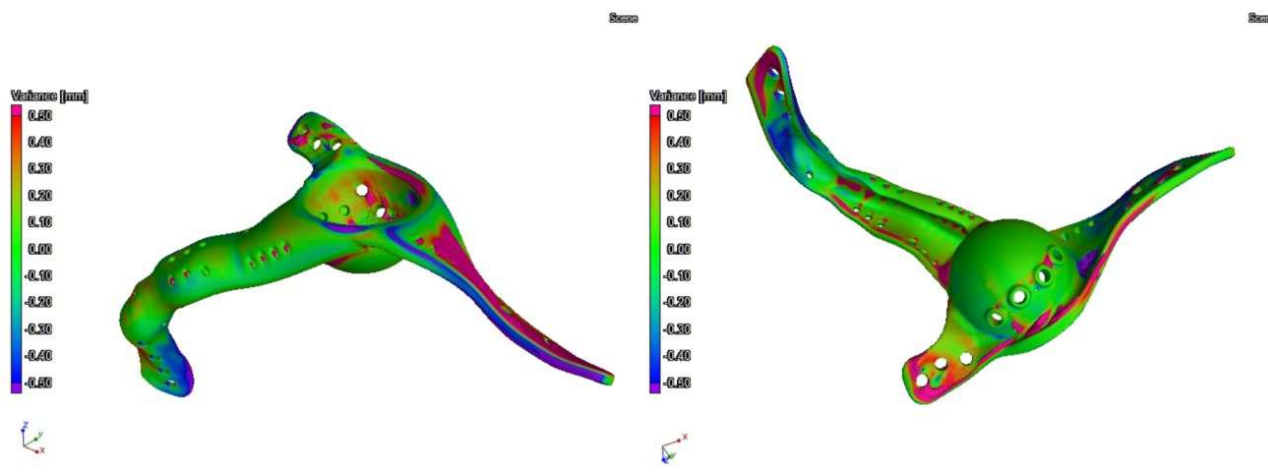

Figure 7 - Hip Socket Implant Including a Part of the Pelvis

\subsection{Defectoscopy}

The defectoscopy means the identification of air bubbles (pores) or foreign materials (inclusion) in the basic material. Air bubbles can be formed due to imperfect manufacture, as the laser fails to fuse the building material at some locations. With regard to the fact that the implant is manufactured from the powder as the basic material, the probability of foreign material presence is minimal. Implant manufacturing is followed by the post-processing that includes also sand-blasting to reduce the surface roughness. In case of the manufacture of implants containing trabecular structures (porous structures facilitating the tissue grow through), these structures might trap the particles of the material intended for the sand-blasting. Its density is different, therefore, it can usually be identified as a significantly brighter point. 


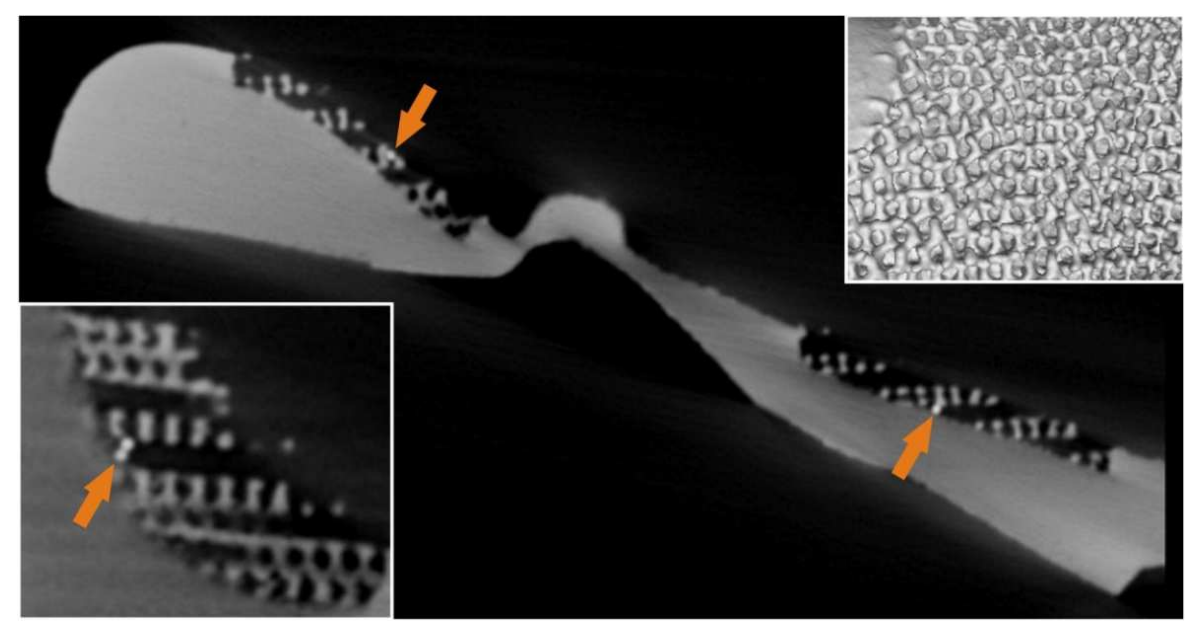

Figure 8-Inclusion (sand-blasting material)

Figure 8 shows the implant cross-section, while the arrows indicate the particles of the material intended for the sand-blasting. In the top right corner there is a detail of the trabecular structure, and the bottom left corner contains a detail of the inclusion from a different view.

To verify the ability to identify the defects during the manufacture process using the industrial computed tomography, an artefact containing artificial cavities was designed and subsequently manufactured. The artefact was manufactured in cooperation with the CEIT Biomedical Engineering s.r.o company using the Eosint M280 machine from the EOS GmbH company, and the basic material used was Ti64 titanium alloy. The artefact drawing is shown in Figure 9.

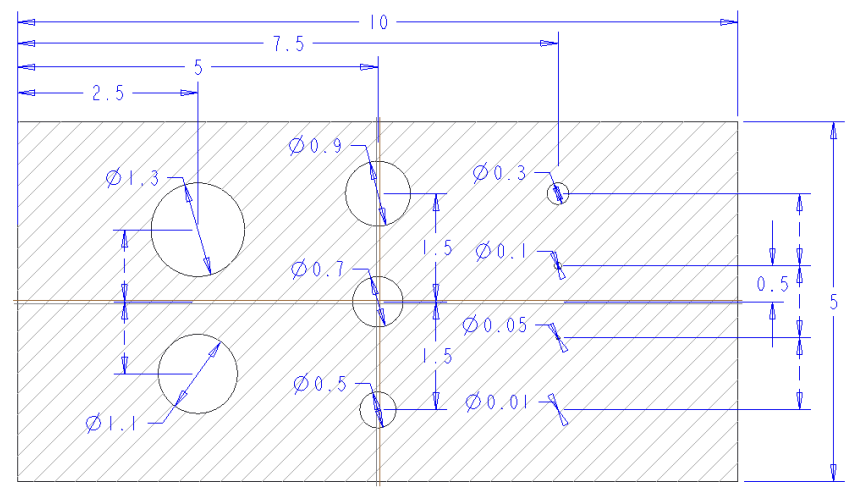

Figure 9 - Artefact Drawing

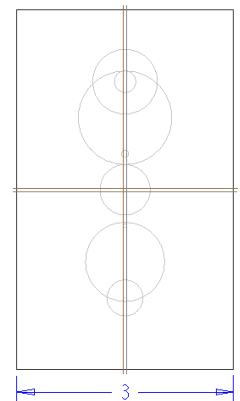

As the manufacturing is carried out layer by layer, all potential cavities are filled with unfused basic powder material. The assessment was carried out using the VGStudioMAX 2.2 software by the Volume Graphics GmbH company. 

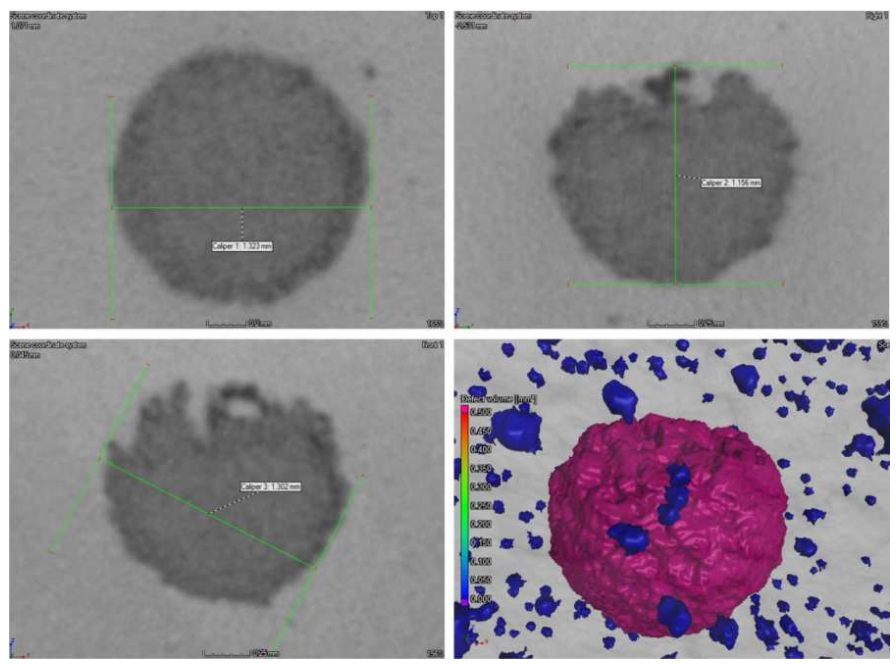

Figure 10 - Pore Representation

Porosity is assessed on the basis of deviations of contrast between the material depicted in the images in grey tones and the air which is black. In case of the designed artefact, the assessment will be focused on the differences between two shades of grey, where the fused material is brighter, and thus of the density higher than the unfused material. Figure 10 shows a pore in three cross-section planes and its reconstruction into 3D.

The designed artefact was scanned with the identical output parameters and only the scanning distance (artefact's position towards the X-ray emitter) was altered. Distance adjustment influences the size of the obtained voxel (volumetric pixel), while it applies that the smaller is the voxel, the higher is the sharpness of the details (Table 1).

Table 1 - Input Data Table

\begin{tabular}{l|l|l|l|l|l|l}
\hline Measurement & $\begin{array}{c}\text { Distance from } \\
\text { X-ray source } \\
{[\mathbf{m m}]}\end{array}$ & $\begin{array}{c}\text { Voltage } \\
{[\mathbf{k V}]}\end{array}$ & $\begin{array}{c}\text { Current } \\
{[\boldsymbol{\mu A}]}\end{array}$ & $\begin{array}{c}\text { Integration } \\
\text { time }[\mathbf{m s}]\end{array}$ & Gain & $\begin{array}{c}\text { Voxel } \\
{[\boldsymbol{\mu m}]}\end{array}$ \\
\hline SN1 & 60 & 165 & 100 & 2000 & 16 & 16.39 \\
\hline SN2 & 200 & 165 & 100 & 2000 & 16 & 53.50 \\
\hline SN3 & 600 & 165 & 100 & 2000 & 16 & 159.54 \\
\hline
\end{tabular}

The results obtained indicate that with the distance of $60 \mathrm{~mm}$, the smallest assessed pore size is $0.3 \mathrm{~mm}$ and the smallest identifiable pore size is $0.06 \mathrm{~mm}$. Smaller assessed pores cannot be identified, thus the manufacture process is probably not able to create an artificial cavity of the given size. With the scanning distance of $200 \mathrm{~mm}$, the smallest identifiable pores size is $0.3 \mathrm{~mm}$, and with the distance of $600 \mathrm{~mm}$, it is $0.5 \mathrm{~mm}$. Natural pores cannot be detected with 
the given distances. Figure 11 shows the outcome for the porosity assessment with the distances of 60,200 , and $600 \mathrm{~mm}$.

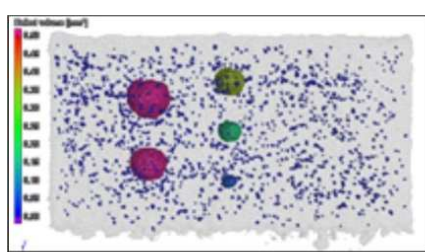

$60 \mathrm{~mm}$

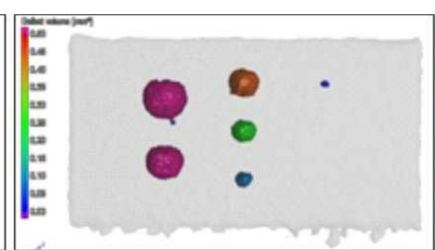

$200 \mathrm{~mm}$

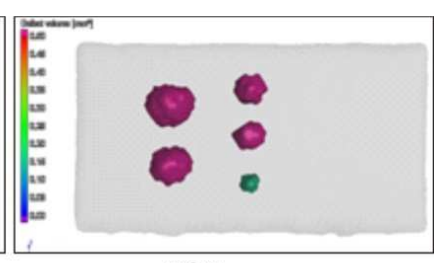

$600 \mathrm{~mm}$

Figure 11 - Comparison of Results

\subsection{Dimensional Analysis}

In case it is required to express numerically the values of deviations at any selected location, it is possible to use a tool enabling, after the objects are aligned and compared, the calculation and representation of a deviation at a particular location (Figure 12). If the dimensions between the components (distances) or the dimensions of individual components are required, it is appropriate to use a specialised tool, e.g. Calypso by the ZEISS company. The dimensional analysis, however, is interesting especially in case of functional dimensions, for example the head diameter etc. in endoprosthesis.
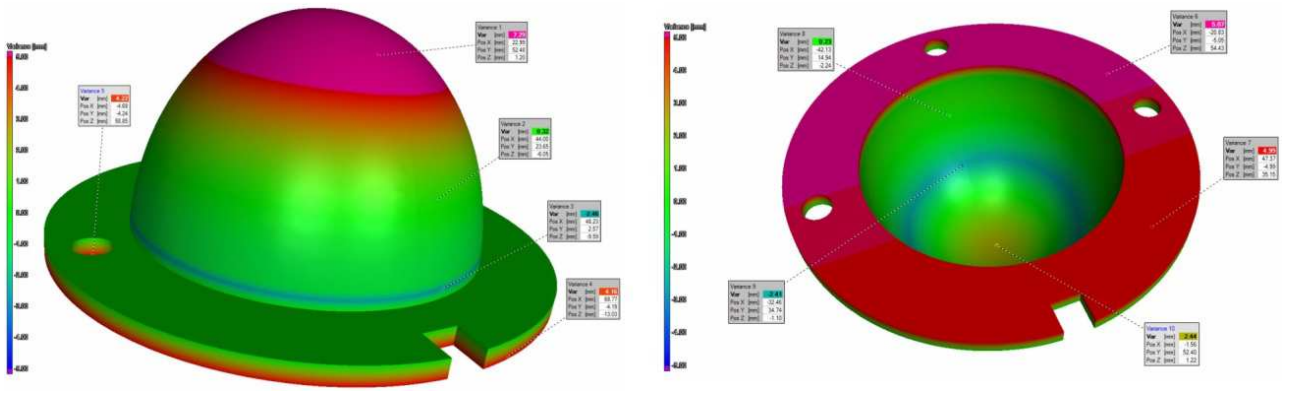

Figure 12 - Dimensional Analysis

\section{CONCLUSION}

The article presents the possibilities of the computed tomography utilisation in the inspection of individual implant manufacture using the additive manufacturing technologies. The results indicate that with the adjustment of appropriate input parameters (alignment), this technology is appropriate for the analysis of shape deviations, when compared with the CAD model. Subsequently, the tools facilitate identification of deviations at any implant location, and after the assessment requirements (tolerances) are determined, the conclusion can be made regarding the outcome's compliance with the requirements. The computed tomography is also a tool facilitating the detection of potential pores and inclusions inside an implant. In this case, the scanning 
distance must be considered, as with the increasing distance the machine's resolution function decreases. With the scanning distance of $60 \mathrm{~mm}$, tiny pores fall within the standard specified by the equipment manufacturer (less than $8 \%$ of the total artefact volume). The dimensional analysis is not preferential for this type of implants; in case of a hip socket implant, the only important dimension from among the above listed examples, is the hip socket diameter.

\section{ACKNOWLEDGEMENT}

Presented manuscript was supported by project Research of New Diagnostic Methods in Invasive Implantology, MŠSR-3625/2010-11, Stimuli for Research and Development of Ministry of Education, Science, Research and Sport of the Slovak Republic, the project "Center for research of control of technical, environmental and human risks for permanent development of production and products in mechanical engineering" (ITMS:26220120060) supported by the Research \& Development Operational Programme funded by the ERDF and project KEGA 036TUKE-4/2013 "Implementation of new technologies in design and fabrication of implants in biomedical engineering and related scientific fields".

\section{REFERENCES}

Bauza, M.B., Moylan, S.P., Panas, R.M., Burke, S.C., Martz, H.E., Taylor, J.S., Alexander, P., Knebel, R.H., Bhogaraju, R., O'Connell, M.T. and Smokovitz, J.D., 2014. Study of accuracy of parts produced using additive manufacturing. In: 2014 ASPE Spring Topical Meeting: Dimensional Accuracy and Surface Finish in Additive Manufacturing. Berkeley, CA, United States, April 13-16, 2014. Available at: http://www.nist.gov/manuscript-publicationsearch.cfm?pub_id=915785 [Accessed 7 September 2014]

Brown Ch., Lubell, J. and Lipman, R.: Additive Manufacturing Technical Workshop Summary Report. Available at:

Drstvensek, I., Hren, N.I., Strojnik, T., Brajlih, T., Valentan, B., Pogacar, V. and Hartner, T.Z., 2008. Applications of Rapid Prototyping in Cranio-Maxilofacial Surgery Procedures. Internacional Journal of Biology and Biomedical Engineering, 2(1), pp.29-38. Available at:

http://www.naun.org/main/NAUN/bio/bio-19.pdf [Accessed 10 September 2014]

Girardin, E., Renghini C., Dyson, J., Calbucci, V., Moroncini, F. and Albertini, G., 2011. Characterization of Porosity in a Laser Sintered MMCp Using X-Ray Synchrotron Phase Contrast Microtomography. Materials Sciences and Applications, 2(9), pp.1322-1330, doi:10.4236/msa.2011.29180.

http://nvlpubs.nist.gov/nistpubs/TechnicalNotes/NIST.TN.1823.pdf [Accessed 1 September 2014] 
Léonard, F., Tammas-Williams, S., Prangnell, P., Todd, I. and Withers, P. 2012. Assessment by X-ray CT of the effects of geometry and build direction on defects in titanium ALM parts. In: Conference on Industrial Computed Tomography (ICT), 19-21 September 2012, Wels, Austria. Available at: http://www.ndt.net/article/ctc2012/papers/91.pdf [Accessed 5 September 2014]

Matilainen, V. 2012. Benchmarking of laser additive manufacturing process. Bachelor thesis. Lappeenranta University of Technology. Available at: http://www.doria.fi/bitstream/handle/10024/84863/BSc\%20Thesis\%20Matilaine n\%20fv.pdf?sequence $=1$ [Accessed 10 August 2014]

Podshivalov, L., Gomes, C.M., Zocca, A., Guenster, J., Bar-Yoseph, P. and Fischer, A., 2013. Design, Analysis and Additive Manufacturing of Porous Structures for Biocompatible Micro-Scale Scaffolds. Procedia CIRP, Volume 5, 2013, pp.247-252, ISSN 2212-8271. Available at: http://dx.doi.org/10.1016/j.procir.2013.01.049 [Accessed 10 September 2014].

Salmi M., 2013. Medical applications of additive manufacturing in surgery and dental care. Doctoral Disertation. Aalto University. Available at: https://aaltodoc.aalto.fi/bitstream/handle/123456789/11854/isbn9789526054964. pdf? sequence $=1$ [Accessed 5 September 2014]

Slotwinski, J.A., Garboczi, E.J., 2013. Porosity of Additive Manufacturing Parts for Process Monitoring. In: $40^{\text {th }}$ Review of Progress in Quantitative NonDestructive Evaluation, July 22-26, 2013, Baltimore, MD. Available at: http://www.nist.gov/manuscript-publication-search.cfm?pub_id=914546 [Accessed 10 August 2014]

Živčák J., Hudák, R., Bednarčíková L., Tóth, T. and Trebuňová, M., 2013. Biomechanisms Individual Implants (In Slovak: Biomechanizmy Implantáty na mieru), Košice: Strojnícka fakulta TU, ISBN 978-80-553-1396-2.

\section{ABOUT THE AUTHORS}

Ing. Teodor Tóth, PhD., Technical University of Košice, Faculty of Mechanical Engineering, Department of Biomedical Engineering and Measurement; Letná 9, 04200 Košice, Slovakia, e-mail: teodor.toth@tuke.sk

Doc. Ing. Radovan Hudák, PhD., Technical University of Košice, Faculty of Mechanical Engineering, Department of Biomedical Engineering and Measurement; Letná 9, 04200 Košice, Slovakia, e-mail: radovan.hudak@tuke.sk

Dr.h.c. prof. Ing. Jozef Živčák, PhD., Technical University of Kosice, Faculty of Mechanical Engineering, Department of Biomedical Engineering and Measurement; Letna 9, 04200 Kosice, Slovakia, e-mail: jozef.zivcak@tuke.sk 